\title{
Considerations regarding the use of technological equipment for indexed and continuous multi-axes machining
}

\author{
Radu-Eugen Breaz ${ }^{1, *}$, and Melania Tera ${ }^{1}$ \\ ${ }^{1}$ Lucian Blaga University of Sibiu, Department of Industrial Machines and Equipment, 55002510 \\ Victoriei, Sibiu, Romania
}

\begin{abstract}
CNC machine-tools are becoming more and more complex, with regards of kinematic capabilities, driving systems, HMI interfaces and controllers. Consequently, the prices of these machines are also increasing, being directly linked with the machine characteristics. Multi-axes kinematic is nowadays seen as the possibility of controlling the motion of the machine elements not only on translational axes, but also on rotational ones. There are mainly two types of CNC milling machines with multiaxes kinematic: indexed $3+1$ and/or $3+2$ axes and continuous 4 and/or 5 axes machines. This work will present some aspects regarding indexed multi-axis and continuous multi-axes machining.
\end{abstract}

\section{Introduction}

The structure and kinematic of CNC machine-tools greatly influences the machining performances. The most important parameter, by this point of view is the overall number of controlled axis of the machine. While 3-axis machine-tools are the most encountered equipment, nowadays 4- and 5-axis CNC machine-tools are gaining ground in front of them. However, there are still a lot of aspects to be taken into consideration to balance the performances and costs.

While 3-axis CNC machine-tools machining capabilities are quite enough for most of the parts within machine-building industry, sculptured surfaces usually require machining performances which can be achieved only by means of 4- and 5-axis CNC machine-tools. However, higher performances require higher cost, related to both equipment and workforce, consequently a comprehensive analysis is needed before taking the decision of using either 3-axis or 5-axis CNC machine-tools.

The work presented in [1] presented a method of performing 5-axis machining on a 3axis machine-tools, by using a rotary-tilting indexing table. The approach presented in [2] proposed a method of using a 3 -axis CNC machine-tool, which has also the capability to perform to supplementary indexed rotations (seen as $1 / 2$ axis), for machining sculptured surfaces. Other researchers have targeted the identification of the deviations of 5-axis CNC machine-tools with tilting-rotary table [3]. To reduce the costs related with buying a new 5-

${ }^{*}$ Corresponding author: radu.breaz@ulbsibiu.ro 
axis CNC machine-tool, some authors proposed methods of equipping 3-axis CNC machine-tools with additional axis [4].

Another problem related with the use of $\mathrm{CNC}$ machine-tools is the collision avoidance. While for 3-axis CNC machine-tools the collisions may occur only between tool and workpiece (and also the fixing device), for 5-axes CNC machine-tools the situation is somehow more complex.

On multi-axis machining, the collision may occur between tool and workpiece but also between tool, workpiece and moving machine elements (slides and or tilting-rotary tables). The more complex the geometry of the part is, the more collision occurrence possibilities are expected, so various methods for avoiding them are presented in the literature [5].

In [6] a method of building a 3D geometric and kinematic model of a 5-axis CNC machine-tool was presented. The use of such a model allow the user to identify and eliminate the collisions during the simulation phase. Consequently, the above-mentioned model must be used in conjunction with a CAM software package, which can simulate the machining process.

\section{The geometric and kinematic model of the machine}

The part presented in figure 1 has five pockets on each face which have to be machined. On a 3-axis CNC milling machine the part can be machined by re-positioning each face, meaning that the part must be un-fixed and fixed again before and after each operation. Also, the technological origin (which is set in the program under G54 address) must be changed for each operation, a fact which usually involves complex and accurate adjustments. Consequently, five setups will be required.
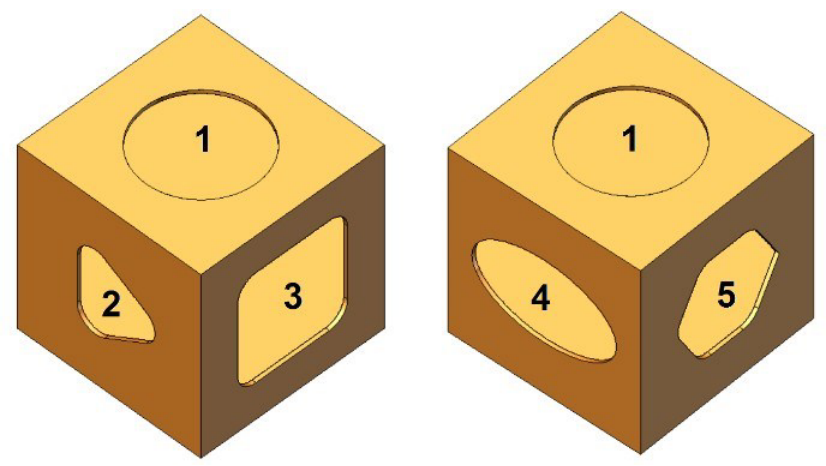

Fig. 1. Part for $3+2$ indexed machining.

On the other hand, on a 5-axis CNC milling machine, the part can be machined using a single setup, by means of a $3+2$ axis machining process. It means that only translational movements (on $\mathrm{X}, \mathrm{Y}$ and $\mathrm{Z}$ axes) will be used during the machining process, while the rotational movements will be used only outside the machining process, just for repositioning the part (indexation), without the need of un-fixing it from the machine table. To illustrate the process of 3+2 machining, the DMF 260-11 DMG Mori-Seiki 5 axis CNC machine-tool was taken into consideration (fig. 2). The machine can rotate the machining head around $\mathrm{Y}$ axis (on $\mathrm{B}$ axis), while the part can be rotated around $\mathrm{Z}$ axis, using a rotary table (on $\mathrm{C}$ axis). Both indexed $(3+1$ and $3+2)$ axis and continuous 5 axis machining operations can be performed on this machine. 


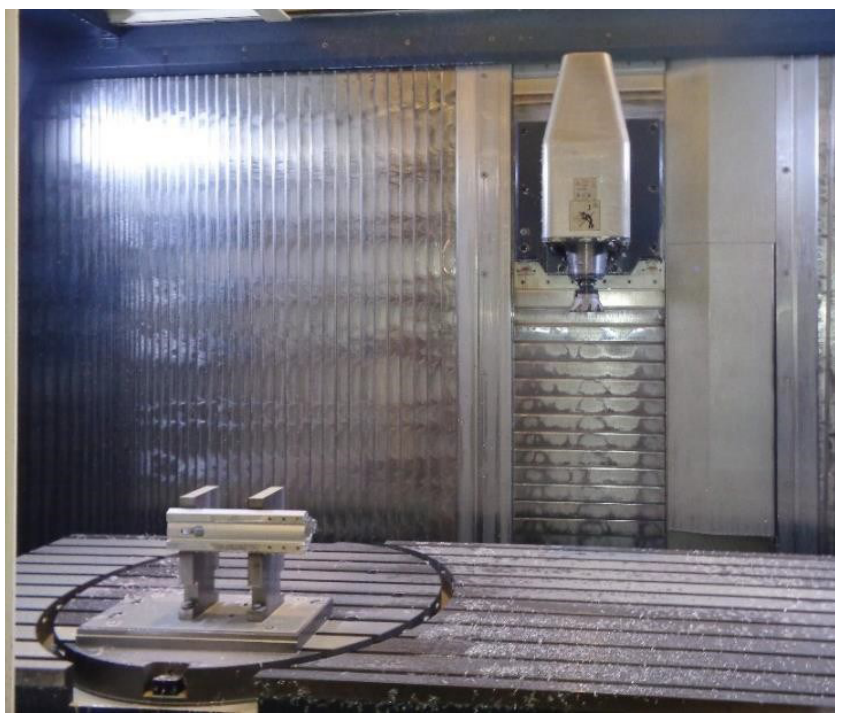

Fig. 2. Workspace of DMF 260-11 DMG Mori-Seiki 5-axis machine-tool.

To machine the part, a CAM software package was used. In a first approach, during the process of generating the NC code, no model of the machine was used. The second approach took intro a consideration a 3D geometric and kinematic model of the machine, presented in figure 3. This model was built by the authors of this paper. A 3D CAD program was used for building the geometric model, while the tools provided by the CAM software package were used to define the kinematic of the machine.

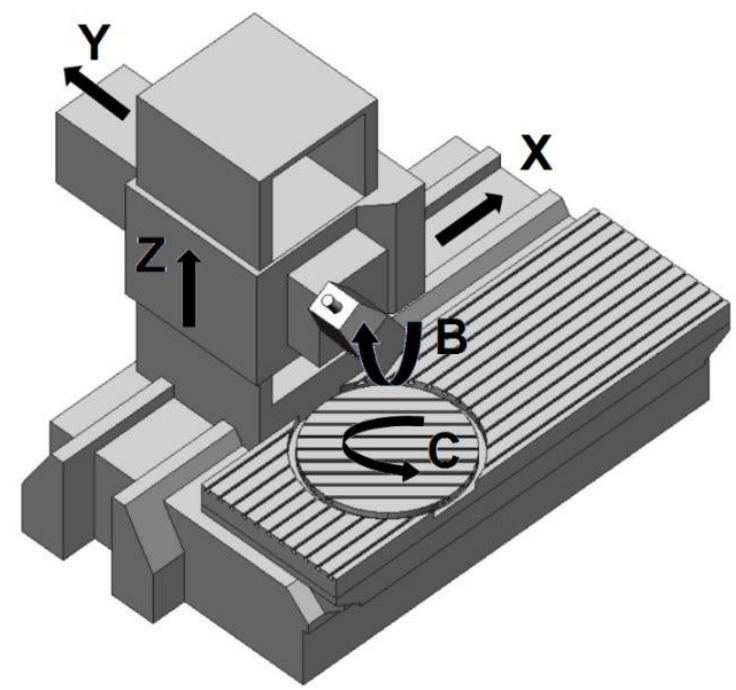

Fig. 3. 3D geometric and kinematic model of DMF 260-11 DMG Mori-Seiki 5-axis machine-tool.

In order to machine the part, five different operations were needed. Aside the first operation, all the other four operations required indexation movements on axes B and C. A scheme of each operation and the values of the $\mathrm{B}$ and $\mathrm{C}$ angles are presented in table 1 . The fixing device (vise) was also taken into consideration for simulating the machining process on the DMF 260-11 DMG Mori-Seiki 5-axis machine-tool. 
Table 1. $3+2$ indexed machining of the considered part.

\begin{tabular}{|c|c|c|}
\hline Operation & Indexation & Scheme \\
\hline Millingofface 1 & $\begin{array}{l}\mathrm{B}=0^{\circ} \\
\mathrm{C}=0^{\circ}\end{array}$ & \\
\hline Millingofface2 & $\begin{aligned} \mathrm{B} & =-90^{\circ} \\
\mathrm{C} & =0^{\circ}\end{aligned}$ & \\
\hline Millingofface3 & $\begin{aligned} \mathrm{B} & =-90^{\circ} \\
\mathrm{C} & =90^{\circ}\end{aligned}$ & \\
\hline Millingofface4 & $\begin{array}{l}\mathrm{B}=-90^{\circ} \\
\mathrm{C}=180^{\circ}\end{array}$ & \\
\hline Millingofface5 & $\begin{array}{l}\mathrm{B}=-90^{\circ} \\
\mathrm{C}=270^{\circ}\end{array}$ & \\
\hline
\end{tabular}


Figure 4 shows how the use of the 3D geometric and kinematic model can identify a collision between a moving machine element (working head rotating on axis B) and the fixing system (vise), while the simulation performed without the use of the model is not able to identify it, because the movements of the machine elements are not simulated.
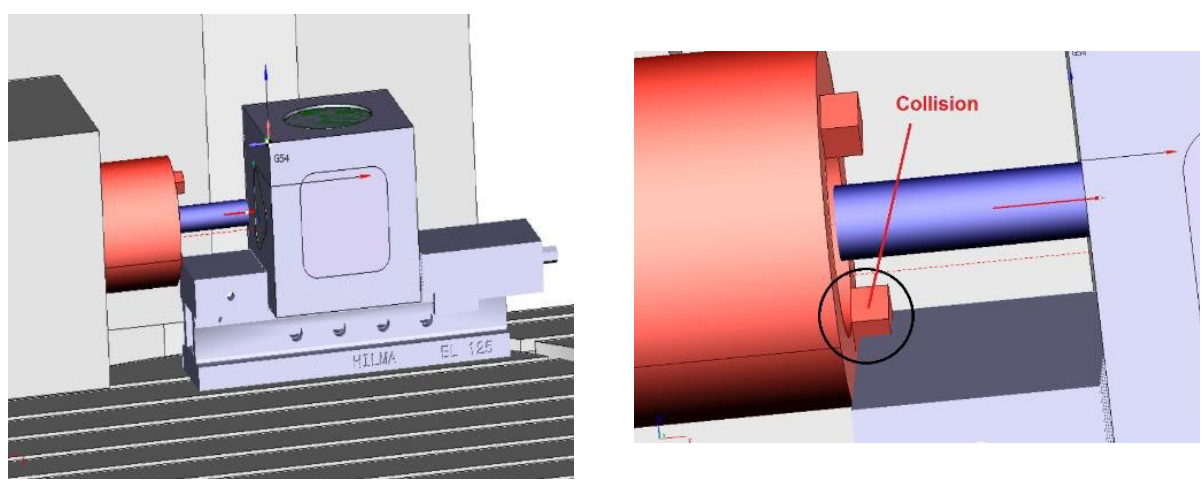

Fig. 4. Collision between a moving machine element and the vise.

\section{Comparison}

Table 2 presents a comparison between the use of 3-axis CNC machine-tools, indexed $(3+2)$-axis CNC machine-tools and continuous 5-axis CNC machine-tools. Paper [7] presents a decision-making tool which assists the user in the process of choosing between 3-axis and 5-axis CNC machine-tools.

Table 2. Comparison

\begin{tabular}{|c|c|c|c|}
\hline Features & $\begin{array}{c}\text { Multi-fixture 3- } \\
\text { axisCNC } \\
\text { machine-tools }\end{array}$ & $\begin{array}{c}\text { Indexed (3+2)- } \\
\text { axisCNC } \\
\text { machine-tools }\end{array}$ & $\begin{array}{c}\text { Continuous5- } \\
\text { axisCNC } \\
\text { machine-tools }\end{array}$ \\
\hline Fixingthepartonthemachine & - & + & + \\
\hline Setting-uptheoriginofthepart & - & + & + \\
\hline Complexityoftheparts & - & + & ++ \\
\hline Machiningaccuracy & - & + & + \\
\hline Costsofthemachine & + & - & -- \\
\hline Costsoftheworkforce & + & - & -- \\
\hline Costsoflogistics & + & - & - \\
\hline
\end{tabular}

It is here noticeable that no solutions have only advantages or only drawbacks. However, if machine-building industry is targeted, one can say that indexed $(3+2)$-axis $\mathrm{CNC}$ machine-tools could represent the best compromise. Sculptured parts, which require 5 -axis continuous milling are not usually encountered in this industry. Moreover, development and acquisition costs related to technological equipment may be dramatically reduced by simply equipping 3-axis $\mathrm{CNC}$ machine-tools with rotary-tilting tables and transforming them into indexed (3+2)- axis CNC machine-tools.

This solution, while allowing the machine-tool to perform rotational movements, is much cheaper, because it does not imply costly upgrades to the $\mathrm{CNC}$ controller, which are needed for 5-axis continuous machining. 


\section{Conclusion}

The work presented in this paper has demonstrated how multi-axis CNC machining can benefit from using 3D geometric and kinematic models during the simulation process. Also, some considerations regarding the advantages and drawbacks of using CNC machine-tools with different kinematic capabilities were presented. Finally, it was stated that a kinematic upgrade of a 3-axis CNC machine-tool in order to transform it in a (3+2)-axis CNC machine-tool could be a better solution than using a 5-axis CNC machine-tool for indexed machining.

\section{References}

1. S.H. Suh, J.J. Lee, J. Manuf. Sci. Eng 120(1), 120 (1998)

2. Z.C. Chen, Z. Dong, G.W. Vickers, Comput. Ind., 50, 319 (2003)

3. M. Tsutsumi, A. Saito, Int. J. Mach. Tool. Manu., 44 (12-13), 1333 (2004)

4. S.H. Suh, J.J. Lee, S.-K. Kim, Int. J. Adv. Manuf. Technol., 14 (12), 865 (1998)

5. S. Ding, M.A. Mannan, A.N. Poo, Comput Aided Des., 36, 1281 (2004)

6. A. L. Chicea, R. E. Breaz, O. Bologa, Applied Mechanics and Materials, 809-810, 1004 (2015)

7. O. Bologa, R.-E. Breaz, S.-G. Racz, M. Crenganiş, Procedia Comput. Sci., 91, 184 (2016) 